\title{
Hand Hygiene Practices among Fifth Year Medical Students in Ibn Sina University, Khartoum, Sudan: Cross Sectional Study
}

\author{
Zaid Ahmad ${ }^{1}$, Hiba Alzaki ${ }^{1}$ and Ahmad Al Juboori ${ }^{2,3 *}$ \\ ${ }^{1}$ Faculty of Medicine, Ibn Sina University, Sudan \\ ${ }^{2}$ Department of Otorhinolaryngology, Head \& Neck Surgery (ORL-HNS), Al Wakra Hospital, Hamad Medical Corporation, Qatar \\ ${ }^{3}$ Weill Cornell Medical College, Ar Rayyan, Qatar \\ *Corresponding author: Ahmad Nasrat Al Juboori, Department of Otorhinolaryngology, Head \& Neck Surgery, Al Wakra Hospital, \\ Hamad Medical Corporation, Qatar
}

\begin{abstract}
Effective hand hygiene is essential for reducing healthcare associated infections. However, compliance of medical students to hand hygiene guidelines are reportedly poor. The aim of present study is to evaluate the awareness and compliance of hand hygiene among undergraduate medical students during their clinical phase in Ibn Sina University, Faculty of Medicine, Khartoum, Sudan. A questionnaire based on World Health Organization's concept of "Five Moments for Hand Hygiene" was used to evaluate the awareness of the indications for hand hygiene and compliance was observed during clinical sessions. Ninety students including forty-two males (47\%) and forty-eight females (53\%) participated voluntarily in the study. The average awareness regarding the positive indications of hand hygiene was $49 \%$. Rest of the $51 \%$ of students was either not sure or unaware of the indications of hygiene. Only $49 \%$ of students were able to identify all the five indications for hand hygiene in the questionnaire. There is disproportion between the results of the students regarding the question of; did you perform hand hygiene after shaking hands of the patient? (It was 48.9\%), but the actual performance which was noted by the examining physician was only $36.4 \%$ of the students who did perform hand hygiene after the general and abdominal examinations. It was concluded that serious efforts are needed to improve the hand hygiene practices among medical students.
\end{abstract}

Keywords: Hand Hygiene; Medical Students; Five Moments for Hand Hygiene

\section{Introduction}

Hand hygiene is considered one of the most important infection control measures for preventing healthcare-associated infections [1]. Hand hygiene is an important healthcare issue globally and is a single most cost-effective and practical measure to reduce the incidence of healthcare-associated infection and the spread of antimicrobial resistance across all setting from advanced health care systems to primary healthcare centers [2,3]. Snow et al. [4] found the medical students to have a low overall rate of hand hygiene. Van De mortal et al. [5] found the nursing students' hand hygiene knowledge and self-reported practices to be significantly better than that of medical students. These infections are the most common adverse events resulting from a stay in the hospital affecting approximately 5 to $10 \%$ of hospitalized patients in the developed world, and the burden is larger in underdeveloped nations. In spite of being a very simple action, compliance with hand hygiene among health care providers is as low as less than $40 \%$ [6-8]. To address this problem of lack of compliance with hand hygiene, continuous efforts are being made to identify effective and sustainable strategies. One of such efforts is the introduction of an evidence-based concept of "My five moments for hand hygiene" by World Health Organization. These five moments that call for the use of hand hygiene include the moment before touching a patient, before performing aseptic and clean procedures, after being at risk of exposure to body fluids, after touching a patient, and after touching patient surroundings. Recent studies have found low awareness level regarding hand hygiene among medical students and certified healthcare providers [9-13]. The aim of the present study was to evaluate the awareness and compliance of hand hygiene among undergraduate medical students during their 
clinical phase in Ibn Sina University, Faculty of Medicine, Khartoum, Sudan.

\section{Material and Methods}

A cross-sectional study was undertaken from March to May 2017 in the College of Medicine, Ibn Sina University, Alban Jaded Hospital, Khartoum, Sudan, after being approved by ethical committee. Activities commonly underwent by medical students during clinical phase $\left(5^{\text {th }}\right.$ year medical students' courses) were selected, and a questionnaire was designed (Figure 1). The compliance of students was assessed during clinical sessions by the teaching physicians who were neither involved in the survey nor were in any way related to formative/summative assessment of the students. Four scenarios based on Moment 1 and Moment 4 was used to assess compliance regarding hand hygiene, and a simple form was used for documentation as shown in Table 1. The participation of students was voluntary, and the questionnaires were kept anonymous. The total number of responses was collected which were 90 students, and data was reviewed and described.

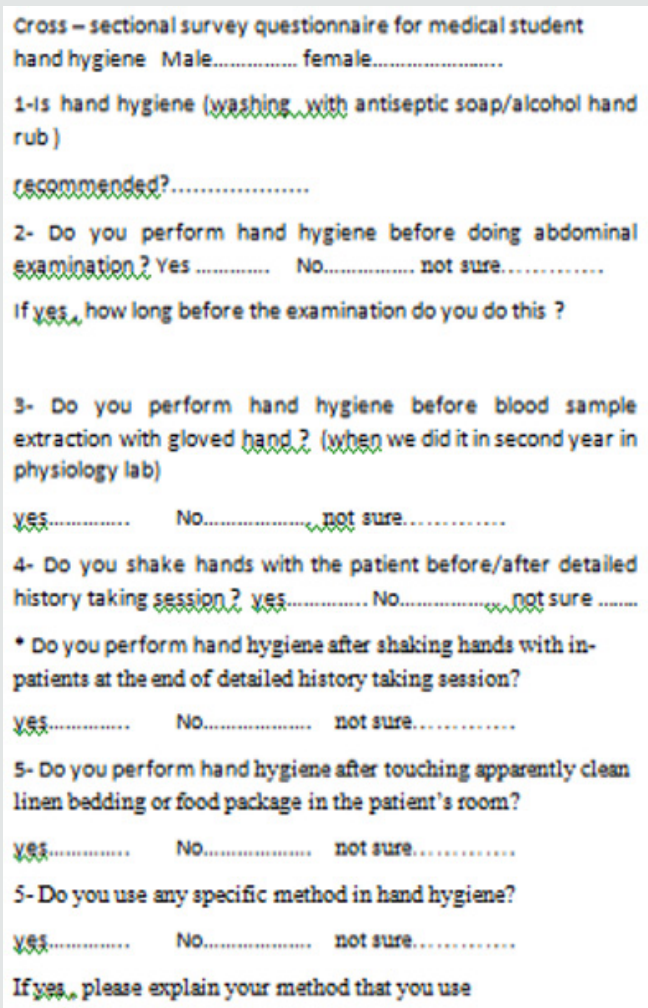

Figure 1: Questionnaire for medical student's hand hygiene.

Table 1: Questionnaire answered by teaching physician for medical student's hand hygiene survey.

\begin{tabular}{|c|c|c|}
\hline Opportunities of Hand Hygiene & $\begin{array}{c}\text { Hand-Hygiene } \\
\text { Observed }\end{array}$ & $\begin{array}{c}\text { Hand-Hygiene } \\
\text { Not Observed }\end{array}$ \\
\hline (1) Before abdominal examination & & \\
\hline (2) After abdominal examination & & \\
\hline $\begin{array}{c}\text { (3) Before general physical } \\
\text { examination }\end{array}$ & & \\
\hline $\begin{array}{c}\text { (4) After general physical } \\
\text { examination }\end{array}$ & & \\
\hline
\end{tabular}

\section{Results}

A total of ninety students were invited to fill the questionnaire. All students (100\%) agreed to participate and subsequently were enrolled in the study. The participating students included $42 \%$ males and $48 \%$ females. The results of questionnaire for medical student's hand hygiene shown in Table 2. Regarding the last question, the student who said yes, the use hand sanitizer $5(5.6 \%)$ and others used antiseptics 1(1.1\%).

Table 2: Knowledge about hand hygiene practice based on WHO questionnaire.

\begin{tabular}{|c|c|c|c|}
\hline Questions & Yes No.(\%) & No & Not sure \\
\hline $\begin{array}{c}\text { Is hand hygiene (washing with } \\
\text { antiseptic soap/alcohol hand rub) } \\
\text { is recommended. }\end{array}$ & $88(97.8)$ & $1(1.1)$ & $1(1.1)$ \\
\hline Do you perform hand hygiene. & $57(63.3)$ & $28(31.1)$ & $5(5.6)$ \\
\hline $\begin{array}{c}\text { Do you perform hand hygiene } \\
\text { before blood sample extraction } \\
\text { with gloved hand. }\end{array}$ & $46(51.1)$ & $37(41.1)$ & $7(7.8)$ \\
\hline $\begin{array}{c}\text { Do you shake hand with the } \\
\text { patient before /after detailed } \\
\text { history taking session. }\end{array}$ & $38(42.2)$ & $39(43.3)$ & $13(14.4)$ \\
\hline $\begin{array}{c}\text { Do you perform hand hygiene after } \\
\text { shaking hands with in patients at } \\
\text { the end of detailed history taking } \\
\text { session. }\end{array}$ & $44(48.9)$ & $29(32.2)$ & $17(18.9)$ \\
\hline $\begin{array}{c}\text { Do you perform hand hygiene after } \\
\text { touching apparently clean linen } \\
\text { bedding or food package in the } \\
\text { patient's room. }\end{array}$ & $53(58.9)$ & $30(33.3)$ & $7(7.8)$ \\
\hline $\begin{array}{c}\text { Do you use any specific method in } \\
\text { hand hygiene. }\end{array}$ & $6(6.7)$ & $77(85.6)$ & $7(7.8)$ \\
\hline
\end{tabular}

The results of questionnaire answered by teaching physician for medical student's hand hygiene survey shown in Table 3.

Table 3: Answers by teaching physician for medical student's hand hygiene survey.

\begin{tabular}{|c|c|c|}
\hline $\begin{array}{c}\text { Opportunities of } \\
\text { Hand Hygiene }\end{array}$ & $\begin{array}{c}\text { Hand-Hygiene } \\
\text { Observed }\end{array}$ & $\begin{array}{c}\text { Hand-Hygiene Not } \\
\text { Observed }\end{array}$ \\
\hline $\begin{array}{c}\text { (1) Before abdominal } \\
\text { examination }\end{array}$ & - & $44(100 \%)$ \\
\hline $\begin{array}{c}\text { (2) After abdominal } \\
\text { examination }\end{array}$ & $16(36.4 \%)$ & $28(63.6 \%)$ \\
\hline $\begin{array}{c}\text { (3) Before general } \\
\text { physical examination }\end{array}$ & - & $44(100 \%)$ \\
\hline $\begin{array}{c}\text { (4) After general } \\
\text { physical examination }\end{array}$ & $16(36.4 \%)$ & $28(63.6 \%)$ \\
\hline
\end{tabular}

\section{Discussion}

Healthcare-associated infection is a very important health issue globally, and hand hygiene is an effective method of infection control. The methods of hand hygiene are widely publicized and simple [2]. Recent studies have found low awareness level regarding hand hygiene among medical students and certified healthcare providers [9-13]. However, the hand hygiene practices have not been studied thoroughly among medical students (trainees) in the Middle East although a few studies have been undertaken on healthcare providers. The present study was aimed to fill this gap and assess the undergraduate medical students 'awareness and 
compliance for hand hygiene. The group studied was in their fifth clinical year that frequently performs activities which must require proper hand hygiene in order not to jeopardize patient's health. In our study, $63.3 \%$ of positive indications for hand hygiene outlined in the questionnaire were correctly identified, and $36.7 \%$ students were either unaware or not sure about these moments. This is comparable to the results that have been reported in literature. Van de Mortal et al. [5] observed that $63 \%$ of medical students were aware of the correct indications for hand hygiene while Mann and Wood [14] reported awareness in only $56 \%$ of students. In our series, only $42.2 \%$ of medical students were able to identify all the indications of hand hygiene. This result is higher to the series of Graf et al. [15], where 33\% of students could do so. Graf et al. used seven scenarios where hand hygiene was indicated in five and not indicated in two, but as the present study was pilot project on the subject, we designed a simpler questionnaire based on five common positive indications for hand hygiene. In near area in the middle East studies, study done in Saudi Arabia showed 56\% of positive indications for hand hygiene outlined in the questionnaire were correctly identified, and $44 \%$ students were either unaware or not sure about these moments, the result near to our study. In our series, only $42.2 \%$ of medical students were able to identify all the indications of hand hygiene. This result is higher to the series of Azzam al Kadi et al. [16]. There is disproportion between the results of the students regarding the question of; did you perform hand hygiene after shaking hands of the patient? (It was 48.9\%), but the actual performance which was noted by the examining physician was only $36.4 \%$ of the students who did perform hand hygiene after the general and abdominal examinations.

\section{Conclusion}

Hand hygiene is the most effective method of preventing transmission of infections. The hand hygiene awareness and compliance among the medical students were found to be very low. There is disproportion between the awareness and the actual performance of the students regarding hand hygiene after general and abdominal examinations.

\section{Ethical Approval}

The case at hand has already been approved by the authors' institution's medical research and ethics committee at the research center.

\section{Declaration of No Conflict of Interest}

All authors declare no financial or personal relationships with other people or organizations.

\section{References}

1. Yuan CT, Dembry LM, Higa B (2009) Perceptions of hand hygiene practices in China. J Hosp Infect 71: 157-162.

2. P. Mathur (2011) Hand hygiene: back to the basics of infection control. Indian Journal of Medical Research 134(11): 611-620.

3. S Kelclkova, Z Skodova, S Straka (2012) Effectiveness of hand hygiene education in a asic nursing school curricula, Public Health Nursing 29(2): 152-159.

4. M Snow, GL White, SC Alder, JB Stanford (2006) Mentor's hand hygiene practices influence student's hand hygiene rates. American Journal of Infection Control 34(1): 18-24.

5. TF Van DeMortel, S Kermode, T Progano, J Sansoni (2012) A comparison of the hand hygiene knowledge, beliefs and practices of Italian nursing and medical students. Journal of Advanced Nursing 68(3): 569-579.

6. Y Longtin, H Sax, B Allegranzi, F Schneider, D Pittet (2011) Videos in clinical medicine. Hand hygiene, The New England Journal of Medicine 364(13): 24.

7. J Tibballs (1996) Teaching hospital staff to hand wash. Medical Journal of Australia 164: 495-498.

8. D Pittet, S Hugonnet, S Harbarth (2000) Effectiveness of a hospitalwide programme to improve compliance with hand hygiene. The Lancet 356(9238): 1307-1312.

9. IA Qushmaq, D Heels Ansdell, DJ Cook, MB Loeb, MO Meade (2008) Hand hygiene in the intensive care unit: prospective observations of clinical practice. Polskie Archiwum Medycyny Wewnetrznej 118(10): 543-547.

10. SZ Bukhari, WM Hussain, A Banjar, WH Almaimani, TM Karima, et al. (2011) Hand hygiene compliance rate among healthcare professionals. Saudi Medical Journal 32(5): 515-519.

11. M Basurrah, T Madani (2006) Handwashing and gloving practice among health care workers in medical and surgical wards in a tertiary care centre in Riyadh, Saudi Arabia. Scandinavian Journal of Infectious Diseases 38(8): 620-624.

12. E Duroy, X Le Coutour (2010) Hospital hygiene and medical students. Medicine et Maladies Infectiousness 40(9): 530-536.

13. A Feather, SP Stone, A Wessier, KA Boursicot, C Pratt (2000) Now please wash your hands': the handwashing behaviour of final MBBS candidates. Journal of Hospital Infection 45(1): 62-64.

14. CM Mann, A Wood (2006) How much do medical students know about infection control? Journal of Hospital Infection 64(4): 366-370.

15. K Graf, IF Chaberny, RP Vonberg (2011) Beliefs about hand hygiene: a survey in medical students in their first clinical year, American Journal of Infection Control 39(10): 885-888.

16. Azzam al Kadi and Sajad Ahmad Salati (2012) Hand Hygiene Practices among Medical Students. Interdisciplinary Perspectives on Infectious Diseases 2012 (11): 679129. 
This work is licensed under Creative Commons Attribution 4.0 License

\section{To Submit Your Article Click Here: Submit Article}

DOI: $10.32474 /$ SJ0.2019.03.000163

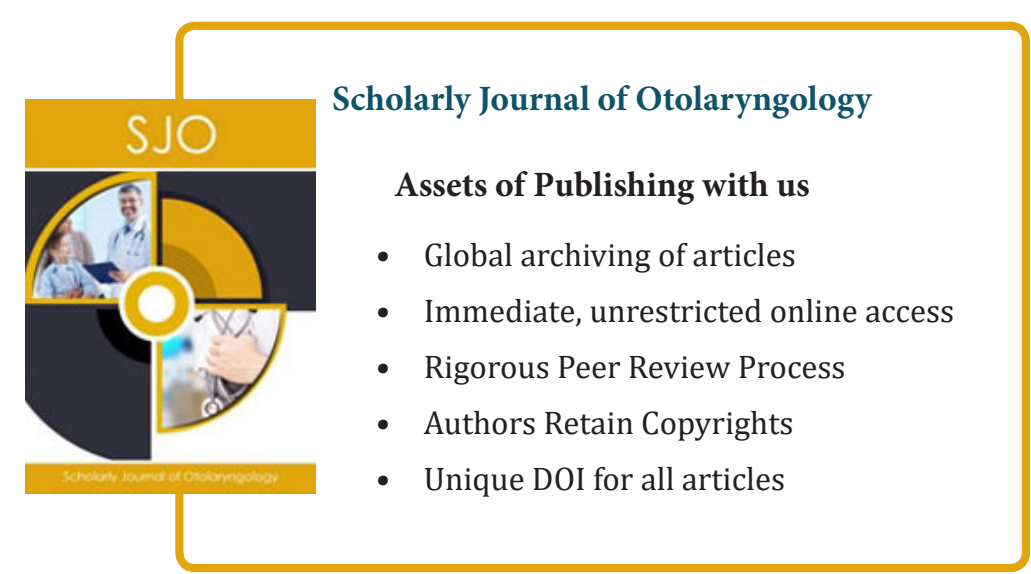

